\title{
ACAT Assessment of Grade-based and Outcome-based Criteria
}

\section{John Glossner, Daniel Webster College}

Dr. John Glossner is President of the Heterogeneous System Architecture Foundation (HSAF) and CEO of Optimum Semiconductor Technologies. OST and its processor division General Processor Technologies (GPT-US). He is also a professor of Computer Science at Daniel Webster College. Previously he served as Chair of the Board of the Wireless Innovation Forum. In 2010 he joined Wuxi DSP (a licensee of Sandbridge technology and parent company of OST) and was named a China 1000 Talents. He previously co-founded Sandbridge Technologies and received a World Economic Forum award. Prior to Sandbridge, John managed both technical and business activities in IBM and Lucent/Starcore. John received a Ph.D. in Electrical Engineering from TU Delft in the Netherlands, M.S degrees in E.E. and Eng. Mgt from NTU, and a B.S.E.E. degree from Penn State. He has more than 40 patents and 120 publications.

\section{Prof. Nicholas Bertozzi, Worcester Polytechnic Institute}

Nick Bertozzi is a Professor of Engineering at Daniel Webster College (DWC) and Dean of the School of Engineering and Computer Science (SECS). His major interest over the past 18 years has been the concurrent engineering design process, an interest that was fanned into flame by attending an NSF faculty development workshop in 1996 led by Ron Barr and Davor Juricic. Nick has a particular interest in helping engineering students develop good communications skills and has made this a SECS priority. Over the past ten years he and other engineering and humanities faculty colleagues have mentored a number of undergraduate student teams who have co-authored and presented papers and posters at Engineering Design Graphics Division (EDGD) and other ASEE, CDIO (www.cdio.org), and American Institute of Aeronautics and Astronautics (AIAA) meetings as well. Nick was delighted to serve as the EDGD program chair for the 2008 ASEE Summer Conference and as program co-chair with Kathy Holliday-Darr for the 68th EDGD Midyear meeting at WPI in October 2013. Nick is currently serving as the Vice Chair of the ASEE EDGD.

\section{Dr. Timothy Daniel Kostar, Daniel Webster College}

Education: BSME, MME, Ph.D. Mechanical Engineering, University of Delaware, Department of Mechanical Engineering and Center for Composite Materials

Assistant Professor and Program Coordinator, Mechanical Engineering: Daniel Webster College, Nashua, $\mathrm{NH}$, (2010-Present).

Senior Composite Aerospace Engineer and Program Manager: Fiber Materials, Inc., Biddeford, ME, (2007-2009).

Senior Engineer and Program Manager: Mentis Science, Inc., Manchester, NH, (2005-2006).

Visiting Assistant Professor: Department of Mechanical Engineering, University of Massachusetts - Lowell, Lowell, MA, (2003-2004).

Design and Advanced Materials Engineer: Advanced Mechanical Design Section, G.E. Aircraft Engines, General Electric Corp., Cincinnati, OH, (2000-2002).

Project Engineer and Program Manager: Composites Technology Division, Foster-Miller, Inc., Waltham, MA, (1998-2000).

\section{Dr. Xinyun David Guo, Daniel Webster College}

David Guo joined Daniel Webster College (DWC) as an assistant professor in engineering after he obtained his PhD degree of Engineering Mechanics of Aerospace in May 2005 from Old Dominion University. In 2010, he was promoted to Associated Professor. He graduated from Beijing Institute of Technology with Bachelor's Degree on Mechanical Engineering and Master's degree in Aerospace Engineering in 1995. 
Dr. Guo teaches undergraduate aeronautical and mechanical engineering courses, develops engineering program curriculum and lab components, and conducts academic research in engineering fields such as nonlinear finite elements, random vibrations, fatigue estimations, and smart materials. His teaching strategy is focusing on improving the overall experience of engineering students by adopting latest teaching philosophy, such as CDIO (Concept, Design, Implement, and Operate) initiative, and making use of advanced teaching tools, such as project-based learning, team-learning, electronic-based learning environment, and laboratory/visualization-aided teaching. So far his students' projects have involved with DBF competition and joint project with UML and University of Colorado Boulder.

He serves as the academic advisor for AIAA student chapter at DWC. He is enthusiastic about aviation/aerospace educations and related applications. He participated AIAA academic conferences as well as student paper conferences regularly.

\section{Ms. Jennifer McInnis, Daniel Webster College Prof. Linda Marquis, Daniel Webster College}

Linda Marquis teaches English composition courses at Daniel Webster College and is the communications specialist for engineering courses. For the latter role, she instructs engineering students in oral and written communications, helping them to advance these skills in their fields. Ms. Marquis has expertise in marketing communications and public relations for the high-technology industry. 


\title{
ACAT Assessment of Grade-Based and Outcome-Based Criteria
}

\begin{abstract}
Building on substantial work done on a new automated course and program assessment tool, we undertook an experiment to determine the accuracy of the outcomes assessments. We compared assessments of course-level outcomes using manual instructor assessments in Moodle and our Automated Course Assessment Tool (ACAT). Four courses taught in the Spring of 2015 were considered. Two are Laboratory courses, and two are traditional book-based courses with exams or projects. We found that in all but one specific case the manual assessment matched the ACAT assessment. In the sole case that did not match, a single indicator attempted to measure all course outcomes simultaneously. The study considered 34 students, 27 outcomes, and used 107 indicators to measure the outcomes. A single indicator affecting two students caused three outcomes to be adjudged incorrectly.
\end{abstract}

\section{Introduction}

Higher education assessment is typically addressed at three levels: course, program, and institution. We have previously presented a developmental Automated Course Assessment Tool (ACAT) that automatically assesses course-level and program-level outcomes. The software works by reading Moodle gradebook entries that instructors have mapped to course-level outcomes. It then computes an assessment of both course-level and program-level outcomes based on these mappings.

An objection to grade-based course-level outcomes has been noted by $\mathrm{ABET}^{1}$. It is desired that course-level outcomes be assessed independent of a final grade for a course. At issue is the accuracy to which a single grade may be applied to a number of course-level outcomes. In our methodology we do not assess an entire course by a single final grade. Our software selects individual Moodle gradebook items to perform the assessment. While this is an improvement, it is sometimes the case that multiple course-level outcomes are assessed by a single gradebook entry. Thus, it still may not provide enough granularity in assessment. 
To validate our approach, the ACAT software has been updated to accept Moodle's course-level outcomes. Our school has run an experiment in which a sampling of courses were evaluated using both gradebook entries and independent assessment of course-level outcomes using Moodle's outcomes. In this paper, we will report on these findings and the correlation between measuring a few course-level outcomes per gradebook item and the independent Moodle-based assessment.

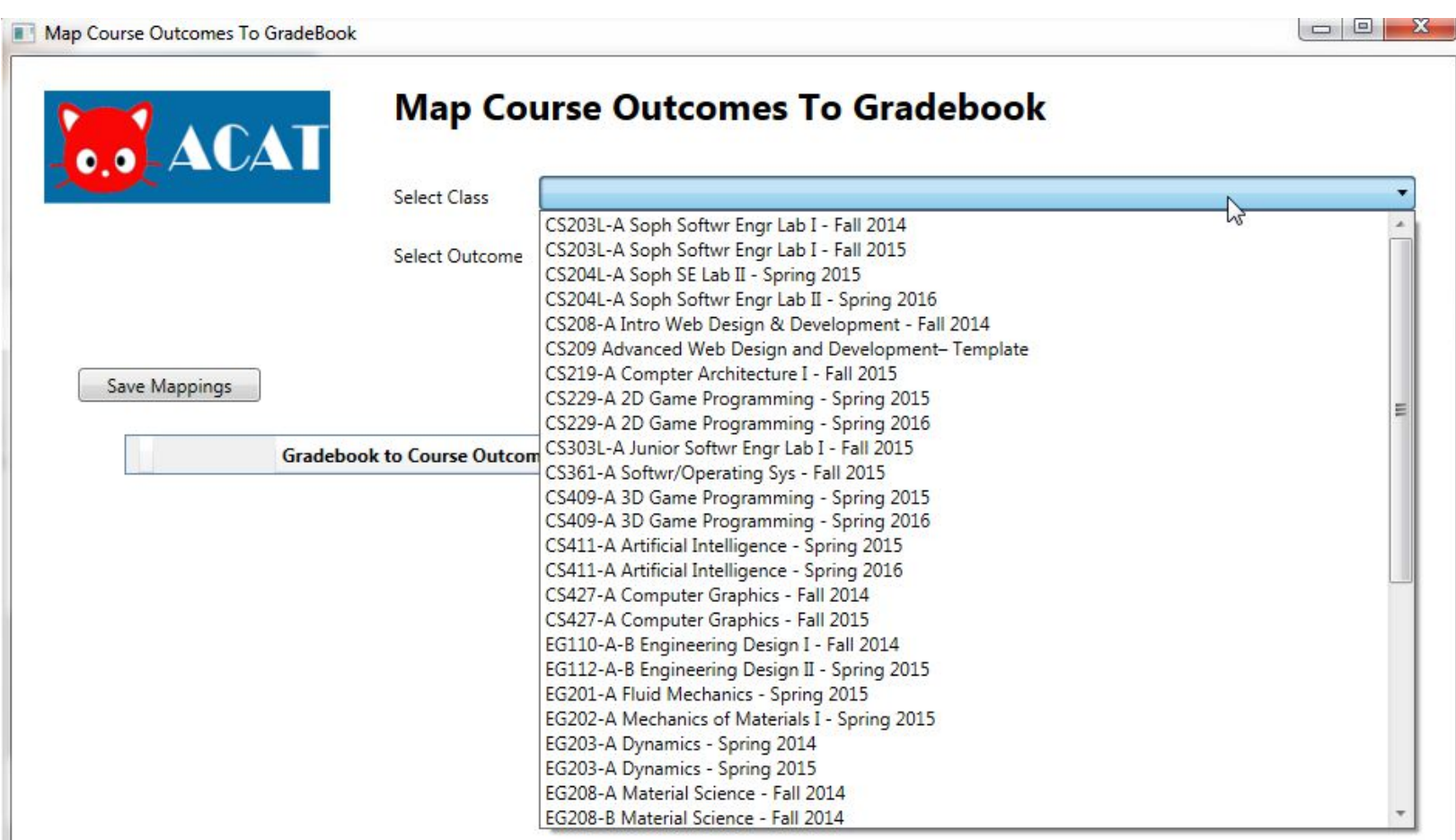

Figure 1. Screen shot showing the instructor's courses and the list of approved course outcomes for ease and consistency of assigning.

\section{ACAT Software}

The Learning Management System (LMS) used by the author's institution is the open source Moodle $^{2}$ LMS. It allows external programs to access its database (e.g., grade book data).

The Automated Course Assessment Tool (ACAT) $)^{3}$ assessment software has been developed at Daniel Webster College for the purpose of assisting end of semester determination of courselevel outcomes and automatic generation of program-level outcomes. Briefly, ACAT maps Moodle gradebook entries to pre-defined course-level outcomes. After logging in, the user 
selects the Define Outcomes menu option.. This will display a window with all the courses the professor is authorized to see. The course instructor selects a course for mapping through a graphical user interface as shown in Figure 1. The instructor is presented only with courses he/she is an approved instructor for.

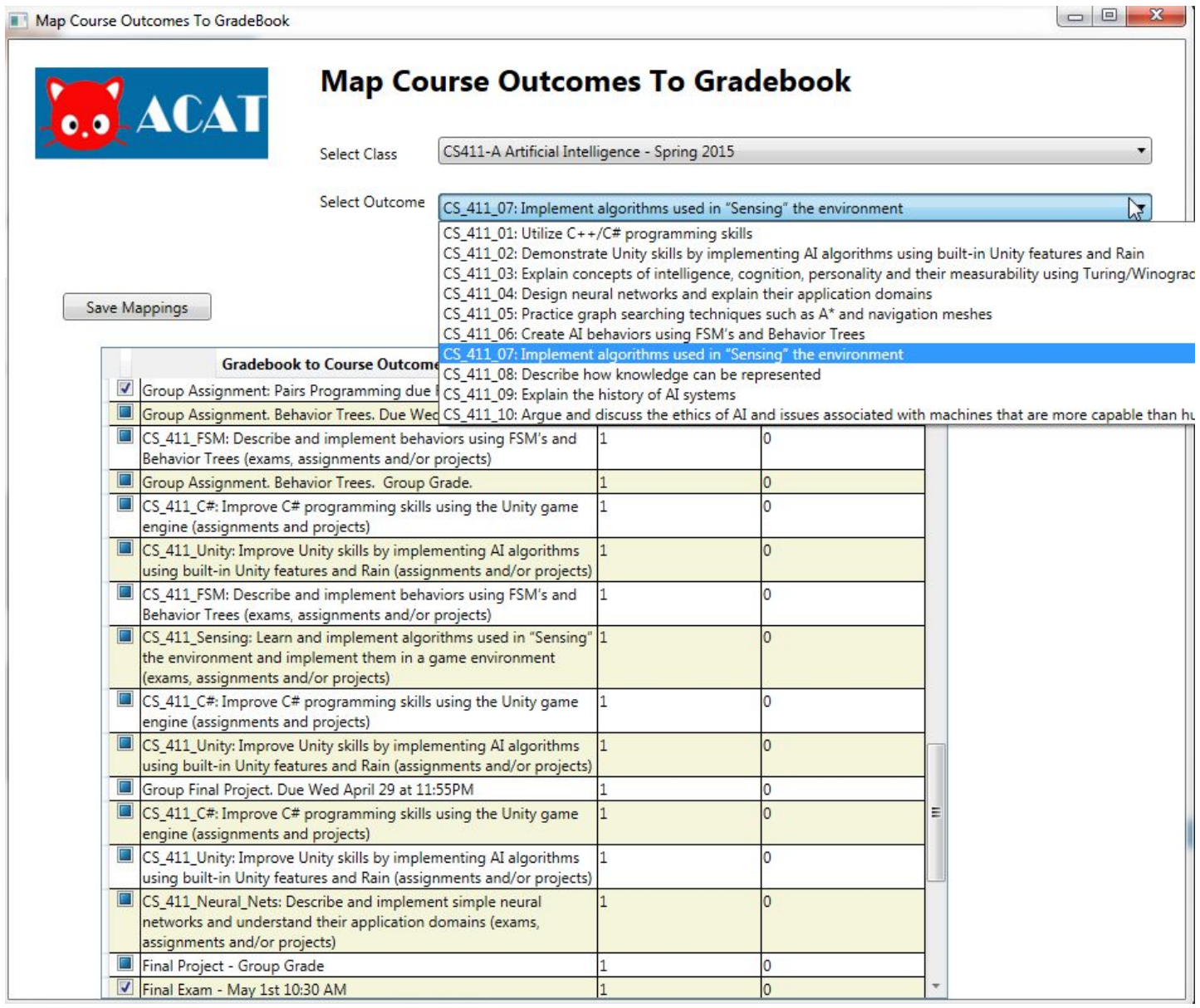

Figure 2. Screen shot showing the Moodle gradebook mappings for a specific course outcome.

Once the course is selected, a dropdown list of course outcomes is automatically as shown in Figure 2. Once an outcome is selected, a table is automatically generated that contains a list of all the Moodle gradebook items for the particular course. The first column is then used to select the specific outcomes for the assessment. Each assessment can be weighted. The third column provides a grade weighting factor, and the fourth column provides a rubric weighting factor. An instructor needs only to select the appropriate checkbox items for each of the course outcomes. After the instructor saves the mappings, both course outcomes and program outcomes are automatically generated. 
Course outcomes must have been previously entered by a Dean or Administrator. The software string-matches the Moodle course-name entry. If no match is found, the software informs the user the course is not available in the database. If it is successfully identified, an instance of the course is created automatically and a database is populated with the currently approved course outcomes. If outcomes change from semester-to-semester, the database course instance contains the historical outcomes that were in effect at the time the course was offered. Having unique identifiers for all course outcomes allows year-over-year comparisons, even if some outcomes have changed.



Figure 3. Screen shot showing the generated course outcomes. 
As shown in Figure 3, once a course has been mapped, the software automatically generates a table that summarizes the percentage of students who met, partially met, or failed to meet each course outcome. The first column lists each outcome. Due to limited screen space, only outcomes 2 through 10 are shown. The second column displays the performance indicators (i.e., Moodle gradebook items) used to evaluate the course outcome. For example, outcome 4 has three indicators. The program normalizes the weights based on instructor inputs during mapping. Since each performance indicator was equally weighted, each contributes one- third of the final evaluation. Columns 4 through 6 show the average grade, number of students, and percent of total students who Meets, Partially Meets, and Fails to Meet the performance indicator. As an example, outcome 2 with performance indicator Individual Project - Slot Machine shows that 3 students ( 3 out of 5, or $60 \%$ ) achieved Meets objectives and their average score was $91 \%$. One student $(20 \%)$ partially meets with a score of $60 \%$. One student also Fails to Meet with a score of $48 \%$. The seventh column gives the average score for a specific performance indicator for all students. Continuing with the slot machine example, the average grade of all students on this indicator was $76.2 \%$. The last column gives the weighted average of all performance indicators for a specific outcome. For outcome 2 , that is $81.9 \%$. Finally, across the bottom of each row, the weighted average per outcome is given. Thus, the weighted percent of students who Meets outcome 2 is 3.5 or $70 \%$ of the class. The number of students who partially meet outcome two is 0.9 students, or $17.5 \%$. The weighted number of students who Fails to Meet is 0.6 students, or $12.5 \%$.

Program-level outcomes are also computed by ACAT using the weighted percent of students calculated in the course-level outcomes. No further instructor input is necessary. Program-level performance indicators are identified and composed from course-level outcomes. Program-level outcomes are composed of a number of performance indicators. These mappings are defined by the Deans or Institutions. Once course-level outcomes are computed, the software uses them to compute the Program-level outcomes ${ }^{3}$. 


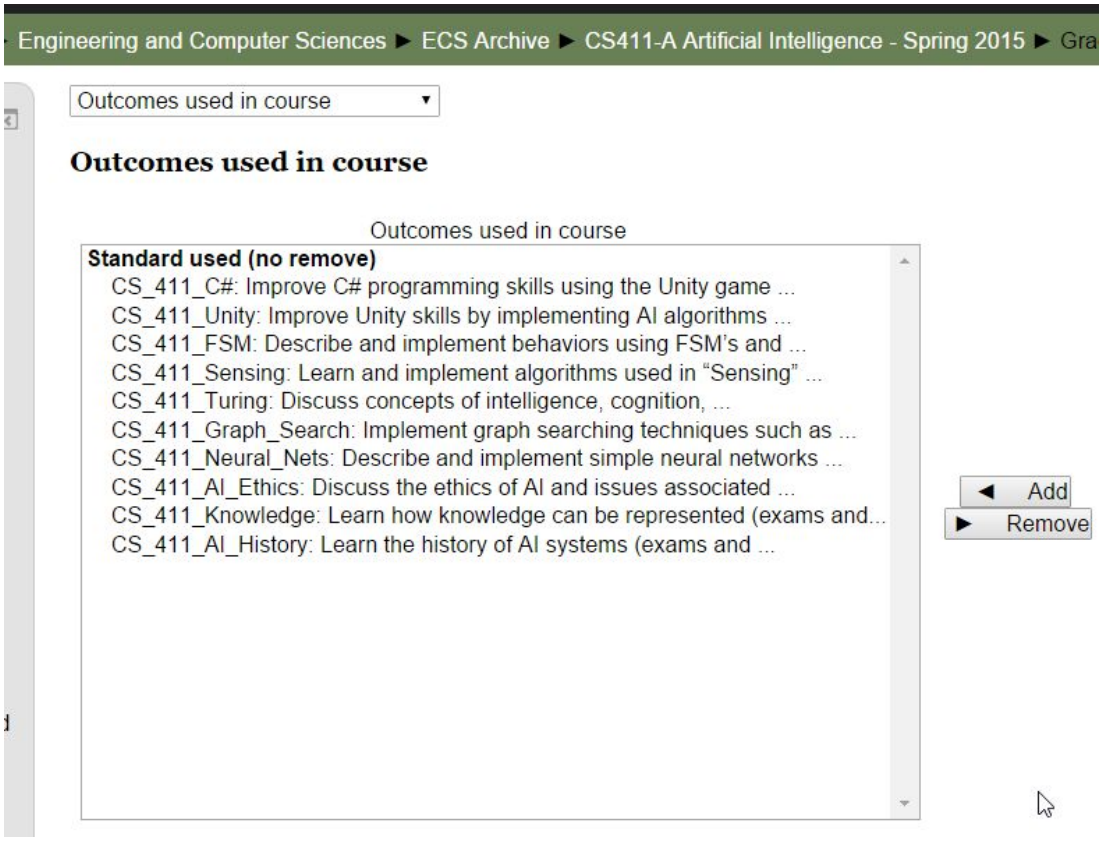

Figure 4. Screen shot showing Moodle course outcomes for CS411 Artificial Intelligence, Spring 2015.

\section{Moodle Assessment}

Moodle also has a built-in course assessment. As shown in Figure 4, course outcomes are first entered into the Moodle database for each course. In this case they are the same outcomes that we use in the automated system.

\begin{tabular}{r|r|} 
CS_411_C\#: Improve & Meets $70 \%-100 \%$ \\
C\# programming skills & \\
using the Unity game & \\
engine (assignments & \\
and projects): & \\
CS_411_Unity: Improve & Meets 70\%-100\% \\
Unity skills by & \\
implementing AI & \\
algorithms using built- & \\
in Unity features and & \\
Rain (assignments & \\
and/or projects): & \\
CS_411_Neural_Nets: & Meets 70\%-100\% \\
Describe and & Meets 70\%-100\% \\
implement simple & Partially Meets 50\%-69\% \\
neural networks and & Fails to meet $0-49 \%$ \\
understand their & No outcome \\
application domains & \\
(exams, assignments & \\
and/or projects): &
\end{tabular}

Figure 5. Screen shot showing assessment of Moodle course outcomes during grading.

We then set up a grading rubric in Moodle for evaluating course-level outcomes. As shown in Figure 5, our institution uses a No Outcome (0) / Fails To Meet (1) / Partially Meets (2) / Meets 
for Outcome Assessment (3) Rubric for Moodle. In ACAT a student meets objectives if his/her score on the activity is $70 \%$ or better. He partially meets the outcome with a score of $50 \%$ to $69 \%$. Below that, the student has failed to meet the objective.

Once Moodle is set up, outcomes are then assigned to Moodle activities (Exams, Assignments, etc.) by selecting the appropriate check boxes for each activity. When an instructor grades an activity, he/she simultaneously and independently assesses the outcomes. This is a manual process in that the instructor provides a score for the activity and a separate assessment of the outcome. This decouples an aggregated grade from the outcome assessment. In the case of a Moodle exam that is automatically graded, this places an additional burden on the instructor due to the manual outcome assessment process.

\begin{tabular}{|c|c|c|c|c|}
\hline \multirow[t]{3}{*}{ CS_411_Turing } & \multirow[t]{3}{*}{$\begin{array}{l}\text { Partially Meets } \\
50 \%-69 \%(2.87)\end{array}$} & \multirow[t]{3}{*}{ Yes } & Homework: Turing Tests. Due Friday 1/16 11:00AM & $\begin{array}{l}\text { Partially Meets } \\
50 \%-69 \%(2.6)\end{array}$ \\
\hline & & & $\begin{array}{l}\text { Homework: Can Machines Think? Due Wed Jan } 21 \text { at } \\
\text { 11:00AM }\end{array}$ & $\begin{array}{l}\text { Meets } 70 \%-100 \% \\
\text { (3) }\end{array}$ \\
\hline & & & Final Exam - May 1st 10:30 AM & $\begin{array}{l}\text { Meets } 70 \%-100 \% \\
\text { (3) }\end{array}$ \\
\hline \multirow[t]{3}{*}{ CS_411_Neural_Nets } & \multirow[t]{3}{*}{ Meets $70 \%-100 \%(3)$} & \multirow[t]{3}{*}{ Yes } & $\begin{array}{l}\text { Homework: Neural Networks. Due Friday April } 10 \text { at } \\
\text { 11:00AM }\end{array}$ & $\begin{array}{l}\text { Meets } 70 \%-100 \% \\
\text { (3) }\end{array}$ \\
\hline & & & Group Final Project. Due Wed April 29 at 11:55PM & $\begin{array}{l}\text { Meets } 70 \%-100 \% \\
\text { (3) }\end{array}$ \\
\hline & & & Final Exam - May 1st 10:30 AM & $\begin{array}{l}\text { Meets } 70 \%-100 \% \\
\text { (3) }\end{array}$ \\
\hline \multirow[t]{4}{*}{ CS_411_Graph_Search } & \multirow[t]{4}{*}{$\begin{array}{l}\text { Partially Meets } \\
50 \%-69 \%(2.9)\end{array}$} & \multirow[t]{4}{*}{ Yes } & Homework: Waypoints. Due Wed March 4 at 11:00AM & $\begin{array}{l}\text { Meets } 70 \%-100 \% \\
\text { (3) }\end{array}$ \\
\hline & & & $\begin{array}{l}\text { Homework: Book Chapter 7. A* Search. Due Friday } \\
\text { March } 6 \text { at 11:00AM }\end{array}$ & $\begin{array}{l}\text { Meets } 70 \%-100 \% \\
\text { (3) }\end{array}$ \\
\hline & & & $\begin{array}{l}\text { Homework: Book Chapter } 8 \text {. Navigation Meshes. Due } \\
\text { Wed March } 18 \text { at 11:00AM }\end{array}$ & $\begin{array}{l}\text { Partially Meets } \\
50 \%-69 \%(2.6)\end{array}$ \\
\hline & & & Final Exam - May 1st 10:30 AM & $\begin{array}{l}\text { Meets } 70 \%-100 \% \\
\text { (3) }\end{array}$ \\
\hline
\end{tabular}

Figure 6. Screen shot showing a partial Moodle course outcomes report for CS411 Artificial Intelligence, Spring 2015.

At the end of the course, Moodle automatically generates an Outcomes report, as shown in Figure 6. In this example we show a subset of three outcomes used in the course. The first column lists the outcome name (e.g. CS_411_Neural_Nets). The second column gives the course average. The third column provides information as to whether the outcome can be used across all courses or is local to a particular course. Global Moodle outcomes are what we refer to as 
Standard Outcomes in ACAT. The fourth column lists the activity that was used for assessment. Of note is that all three outcomes shown in Figure 6 use the Final Exam activity to assess each outcome. The fifth column provides the average assessment of all participants for that activity. In the first row the average of 2.6 is computed from 4 students meeting and 1 student failing to meet the outcomes $((4 * 3+1 * 1) / 5=2.6)$. The overall average in column 2 is the average of all activities $((2.6+3+3) / 3=2.87)$. In Moodle it is not possible to assign a weight to an outcome. The last column identifies the number of students that participated in the activity.

A limitation of the current Moodle system is that outcomes are assigned to the entire Quiz activity and not individual questions within a quiz. Manual assessment of the outcome is a burden to instructors. At the time of this writing there are proposals to assign outcomes to individual quiz questions. One commercial branch of Moodle supports this capability ${ }^{4}$. This allows automatic assessment of Quiz outcomes.

\section{Experimental Process and Results}

To evaluate the effectiveness of ACAT gradebook assessment of outcomes versus manual assessment, an initial study was performed during the Spring 2015 semester. Four courses were selected for both manual Moodle evaluation and automated ACAT evaluation. Two courses were Laboratory group-based learning using $\mathrm{CATME}^{5}$ peer assessment. Manual assessment was based on the individual grade computed using the CATME contribution factor. The first class, Game Design and Development Capstone Project (GD426), had a 1-to-1 mapping between activities and gradebook entries. It was therefore expected that manual and automated outcome measurements would match exactly. The second class, Sophomore Software Engineering Lab II (CS204L), is similar to GD426 except that one Moodle Quiz activity on software engineering design patterns was administered. However, since this quiz measured only a single course outcome, it was also expected to have identical manual and automated assessments.

Two instructional courses were also selected for dual evaluation. The first was 3D Game Programming (CS409). The second was Artificial Intelligence (CS411). These courses had traditional homework assignments that generally evaluated one outcome. However, they both had exams or projects where multiple outcomes were measured both manually and using the 
automated ACAT software. These courses also had group activities where CATME was used to assess individual performance and outcomes determined consistent with the Laboratory courses. In all cases except one outcome, the instructor-based outcome assessment was identical to the ACAT automated assessment.

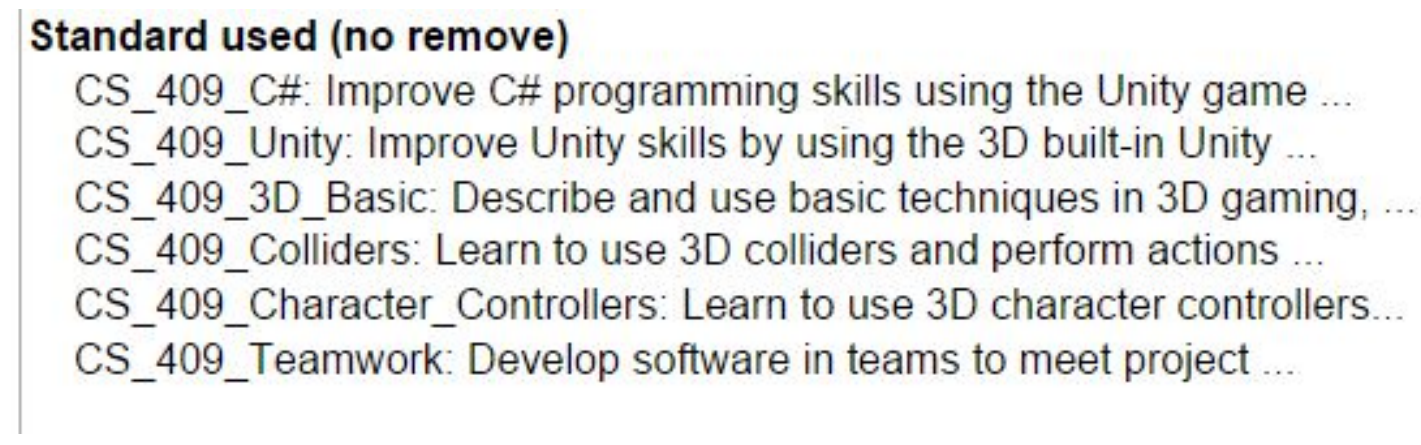

Figure 7. Screen shot showing 3D Game Programming (CS409) standard outcomes

CS411 had five students enrolled in the class. With 10 outcomes to measure, including a final exam that measured multiple outcomes, ACAT and the manual assessment were equivalent. CS409 is the only class where ACAT and manual assessment diverged. Fourteen students were enrolled. Figure 7 shows the 6 outcomes being assessed. One particular indicator, a Group Project, measured all 6 outcomes. Of the 6 outcomes, 3 of them matched the ACAT assessment. However, an instructor evaluation of each outcome showed two of the fourteen students failed to meet 3 outcomes. Specifically, C\# programming, Unity, and Basic 3D techniques were manually adjudged to have not been met for two students, even though they had achieved a passing grade for the project.

In summary, the study considered 34 students, 27 outcomes, and 107 indicators to measure the outcomes. A single indicator affecting two students caused three outcomes to be adjudged incorrectly.

\section{Conclusions and discussion}

Since ACAT uses the final individual score of the indicator to assess all outcomes, it is possible for divergences to arise in comparison with manual assessment. The largest class with 14 students identified one such divergence. This also suggests that it may be desirable to the extent 
possible to design indicators that don't attempt to measure large numbers of outcomes. This is analogous to using a single grade to assess outcomes.

An observation is that the Exams, which also measured multiple outcomes, did not show any divergences. This may be due to a small sample size. CS409 did not have a final exam. Notably, ACAT can also use Moodle Outcomes directly because they appear as gradebook entries.

Moodle has a roadmap to allow outcomes to be assigned to individual Quiz questions. When this feature is implemented, it will be possible in many cases to automatically assess student outcomes with no instructor mappings required. A further enhancement for non-Quiz outcome assessment would be to allow an outcome to be assigned to a Moodle grading rubric. With this addition, the instructor would automatically assess the outcome when he/she scores the activity using the rubric.

In courses not included in this study, both projects and exams have been broken into multiple grade items to enable the assessment of multiple outcomes. For example, in Engineering Design I (EG110), the class project has separate grade items for communication, mechanical design, and control system aspects of the project. In Instrumentations and Measurements (EG207), exams are split into grades for programming, sensor usage, and statistics. In both cases, the single aggregate grade would be insufficient for assessing all of the course outcomes addressed by the activity as seen in CS411. With the divided grades, separate assessment is easy to automate and should avoid the mismatch of assessment seen in this study.

In summary, in all but one case the current gradebook assessment methodology matches the manual Moodle assessment. The small sample size requires further investigation. The case that did not match was analogous to using a single grade to assess all outcomes. Future work should attempt to identify what granularity is acceptable between one activity per outcome and one activity for all outcomes.

\section{Bibliography}

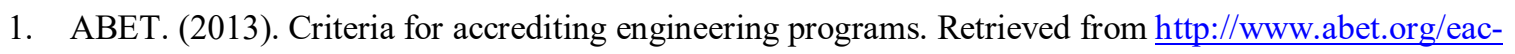
criteria-2014-2015/ on 12/28/2015. 
2. Moodle (2015). Open Source Learning Platform. Retrieved from https://moodle.org/ on 12/28/2015.

3. Kostar, T. D., \& Glossner, J., \& Marquis, L., \& Bertozzi, N. (2015, June), Development and

Implementation of an Automated Course and Program Assessment Tool (ACAT) Paper presented at 2015 ASEE Annual Conference and Exposition, Seattle, Washington. 10.18260/p.23851

4. Moodle Rooms. http://www.moodlerooms.com/five-things-you-need-know-start-using-new-outcomesjoule/ as accessed on 3/12/2016.

5. CATME. http://www.cateme.org as accessed 1/30/2016. 